\title{
Shall We Go to the MALL? - Students' Perceptions of a Business English Learning App
}

\author{
Yu-Chun Wang and Liwei Hsu
}

\begin{abstract}
The study reported in this paper investigated students' perceptions of an application (app) by which mobile-assisted language learning was used to learn business English. An app was developed for purposes of the research. The technology acceptance model was adopted to examine the intent to use the app and find relationships among acceptance variables. One-hundred students of engineering programs at a university in Taiwan joined this study and they were asked to use the app and report on their perceptions. Subsequently, thirteen of the participants also took part in a process of reflection, designed to gain a deeper understanding of their first impressions and perceptions of the app and the associated learning process. It was found that they had a positive attitude toward use of the app for business English learning and were willing to use it. Perceived ease of use was a major factor impacting their perceptions of use of the app for language learning. Furthermore, perceived satisfaction correlated with future behavioral intention; when students were satisfied with the system, they were more accepting of the learning tool. Finally, the students' feedback and suggestions implied that the app enhanced their language proficiency, indicating that mobile-assisted language learning continues to make progress in such contexts.
\end{abstract}

Index Terms-App characteristics, mobile-assisted language learning, technology acceptance model.

\section{INTRODUCTION}

English is the most common second language among individuals from non-native English speaking countries. With the rise of globalization in markets and trade, English has become the most important language by which to communicate and negotiate in business fields [1]. In non-English speaking countries such as Taiwan, in order to successfully communicate with others of various language backgrounds, having high level of proficiency in English is essential in job hunting. To answer this call, vocational colleges in Taiwan attempt to offer their students with English for specific purpose (ESP) courses because such courses can provide learners with domain knowledge and English knowledge simultaneously. According to [2], ESP focuses on the "specific communicative needs and practices of particular social groups." Learners can acquire practical and professional language skills through an ESP program.

In terms of English as a foreign language (EFL) learning, technology can support learning and teaching in various ways; it has the potential to change a student's role from a

Manuscript received October 6, 2019; revised December 19, 2019.

Yu-Chun Wang is with the National Kaohsiung University of Science and Technology, Taiwan (e-mail: willie_wang@ nkust.edu.tw).

Liwei Hsu is with National Kaohsiung University of Hospitality and Tourism, Taiwan (e-mail: liweihsu@mail.nkuht.edu.tw). passive to an active one by means of a variety of activities [3], [4]. With the expeditious development of information communication technology (ICT), mobile devices have become a major role in computer assisted language learning [5]. Mobile learning (m-Learning) allows student-centered learning, in which learners can experience multimedia, complete a variety of activities, and enjoy a more interaction-focused learning process. Flexibility, low cost, small equipment size, and user-friendliness are among the advantages of mobile technology [6]-[9] mentioned that $\mathrm{m}$-Learning enable learners experience real-world feelings and emotions by interacting with learning material and the real environment, enhancing their learning interest and motivation. Previous research on mobile-assisted language learning (MALL) has tended to explore learner's perceptions of the functions of the mobile device and its usability in the field of education [10]-[12]. Few studies have examined the perceptions of students using mobile devices for learning. To fill this research gap, this present study aims to answer the following questions:

1) What are the major factors which influence EFL learners' acceptance of Business English learning APP?

2) What are EFL learners' feedback about their experience of using Business English learning APP?

To appropriately address the proposed research questions, pertinent literature about technology acceptance model (TAM) are reviewed to develop the research framework of this present study. The factors included in the research framework are perceived ease of use (PEU), perceived usefulness (PU), behavioral intention (BI), app characteristics (ACs), perceived enjoyment (PE), perceived mobile value (PMV), and perceived satisfaction (PS). Moreover, we develop a business English learning application (app) named "English Messenger: Business Situational Conversation for Beginners," providing practical content for English learners. Detailed information about this app would be reported in-depth in the methodology section. Additionally, research design such as participant, research procedure, and measurement are described in this section as well. Results of statistical analysis and interview are reported followed by discussion and conclusion section.

\section{LITERATURE REVIEW}

\section{A. Technology Acceptance Model (TAM)}

The TAM, originally proposed by [13], can explain or predict user acceptance of technology. This model had been extensively investigated and found to be powerful, consistent, reliable, and valid [14]. The TAM covers three factors, 
namely perceived ease of use (PEU), perceived usefulness (PU), and attitude toward use [13], the latter of which relates to the degree to which a person believes that using a particular system is free of effort. Perceived usefulness reflects the degree to which a person believes that using a particular system may enhance his or her job performance. [13] proposed that a user's attitude toward a system is the major determinant of whether s/he will accept or reject it. In addition, a user's attitude is influenced by perceived usefulness and perceived ease of use of a technology, the latter having a direct influence on the former. [15] found that users may be influenced by other factors as well. They proposed that external variables could directly influence perceived usefulness and perceived ease of use. They reported on changes in users' attitudes using intention, which included users' attitudes toward actual behavior and subjective norms associated with the relevant behavior (see Fig. 1).

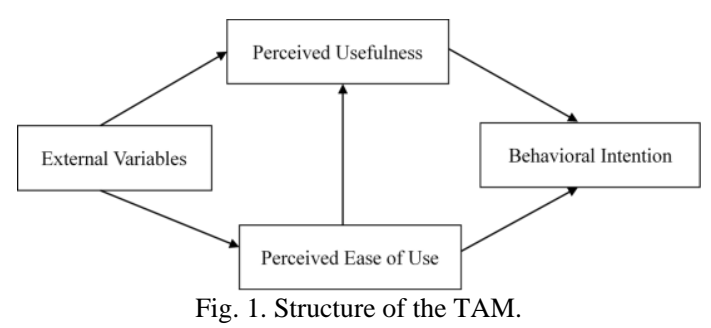

The TAM was originally applied in the field of information systems; however, it extended its application to various other technologies, including those in education [16], [17] including mobile assisted language learning. For example, [18] developed a ubiquitous English vocabulary learning system and used the TAM to analyze student perspectives. The TAM was found to explain users' acceptance-related attitudes. Results showed that active students were more interested in perceived usefulness, which considered whether the learning system enhanced their English ability. Passive students, in contrast, were more interested in perceived ease of use. Such findings indicate that the TAM is a well-established and powerful model for predicting user acceptance.

Determination consists of a range of elements. In the educational field, learners' learning perceptions are influenced by the learning material, learning environment, time, etc. According to [15], external variables may influence perceived usefulness and perceived ease of use. Therefore, within the context of mobile assisted language learning, App characteristics (ACs), perceived mobile value (PMV), perceived enjoyment (PE), and perceived satisfaction (PS) are important elements in users' perceptions [17]-[20]. Hundreds of thousands of apps are currently in use, and their function and content have become important elements people take into consideration when choosing apps. Apps may combine various types of multimedia, audio, animation, and text. These elements can provide users with experience-simulating environments, thereby motivating learning. Therefore, characteristics of any App critically influence learners' perceptions. Mobile value reflects the greatest advantage for learners, allowing them access to a learning program without restrictions of time and place. [19] concluded that mobility may allow guidance and support for learners in new learning situations, with feedback as and when necessary. Furthermore, the learning process is an important element influencing perception. Perceived enjoyment occurs when the use of a system is perceived as enjoyable in its own right, aside from any performance consequences [20]-[22]. Once learners enjoy using an app to acquire knowledge, the degree of acceptance of the app as a learning tool increases. For this reason, its perceived enjoyment is considered an important element influencing learner's perceptions. Learning satisfaction reflects a learner's perceptions and feelings about achieving success [23].

\section{B. Research Model}

The purpose of the present study was to analyze learners' perceptions of the use of the English Messenger app in learning business English. Based on the above review of the literature a conceptual framework (see Fig. 2) and eight hypotheses were formulated. Details about the underlying rationale of research hypotheses are explicated below:

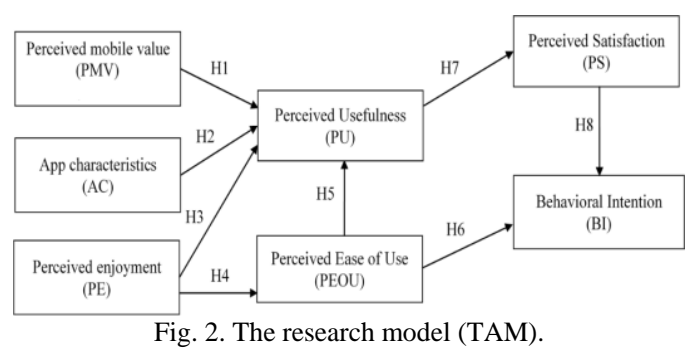

Mobile assisted language learning (MALL) allows learners to optimize the value of mobile devices and apps (PMV) in learning. Such use is not restricted in terms of time or place, providing more learning opportunities which also refers to its perceived usefulness (PU). MALL therefore provides learners more space and freedom, allowing them to set their own pace to accomplish certain activities [19]. In this regard, the first hypothesis was as follows:

H1. PMV has a positive effect on PU.

Furthermore, apps can combine various types of multimedia, images, animation, and text, providing learners opportunities to experience realistic environments during the learning process. Such App characteristics (ACs) can encourage learners to accomplish certain activities, overcoming weaknesses of traditional learning approaches. Once learners experience these ACs, they may be motivated to accomplish the associated learning [18]. In this regard, the second hypothesis was as follows:

H2. ACs have positive effects on PU.

Enjoyment can also support learners in accomplishing learning activities. Certain app features allow learners to experience a unique learning process. Moreover, perceived enjoyment is considered an external variable that influences both perceived ease of use and perceived usefulness [7, 20-22]. This led to two further hypotheses:

H3. PE has a positive effect on PU.

H4. PE has a positive effect on PEU.

Based on [13], perceived ease of use and perceived usefulness are the two central factors influencing users' behavioral intention (BI) to use any particular technology. 
Previous research [13]-[18] has shown PEU, PU, and BI to be related, leading to two further hypotheses:

H5. PEU has a positive effect on PU.

H6. PEU has a positive effect on BI.

Finally, humans experience satisfaction when they engage in certain preferred behaviors. Research has found that learners' perceived satisfaction (PS) is related to the quality of the learning system, learning material, and instruction [23], [24]. When learners are highly satisfied, their intentions become stronger. Thus, if they believe an app can enhance language proficiency, they are more likely to use it. This led to the final two hypotheses:

H7. PU has a positive effect on PS.

H8. PS has a positive effect on BI.

\section{Methodology}

\section{A. APP Design}

Most current students have smart phones or other mobile devices. Students at post-secondary level in Taiwan typically have only one weekly two-hour business English class. To increase learning time and provide learners with more opportunities to acquired extracurricular knowledge about business English, the English Messenger app was designed. This app provides simulated business environments for learning business English (see Fig. 2). Learners can develop their English proficiency by using the app and utilizing various genres of app characteristics, such as multimedia, images, animation, audio, and text. [25] proposed that learning through a multimedia program may result in improved learning outcomes. [25] design principles for multimedia messages were applied in the app's development, including the principles of multimedia, segmentation, coherence, redundancy, spatial contiguity, temporal contiguity, and personalization. Thus, during the learning process, learners could acquire knowledge through words, images, and audio presented simultaneously, efficiently enhancing their language abilities in line with [25] principles.

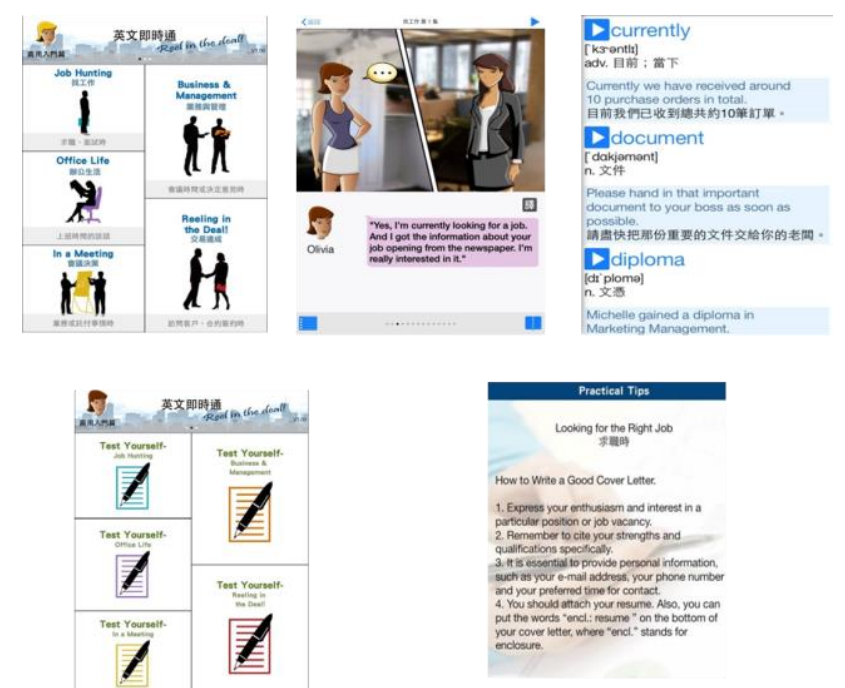

Fig. 3. Snapshots of English messenger for business English APP.

The title of this app was "English Messenger: Business Situational Conversation for Beginners" which included material on five topics: a) job hunting, b) office life, c) attending a meeting, d) business and management, and e) making deals. Each topic was covered by three to five units consisting of conversation, vocabulary, tests, and business tips. Conversations of four native English speakers with different accents (namely, American, Canadian, British and Australian accent) were recorded, and learners could practice their accent and speaking speed as if talking to real English speakers with different accents. The vocabulary section, in turn, provided learners with pronunciation cues, phonetic representations, speech samples, a glossary, and practice sentences.

\section{B. Participants and Procedures}

This research was conducted among 100 undergraduate and graduate students $(n=100)$ aged 18 to 25 years majoring in engineering, electrical engineering and computer science at the National Kaohsiung University of Applied Sciences in Taiwan. All volunteered to participate and were informed that participation held no penalty and that all data would remain confidential. Participants were required to use the English Messenger app in learning business English for one week, having been briefed on its operation and the purpose of the research. After the week, participants completed an online questionnaire targeting their opinions on the app. Finally, thirteen of the participants also took part in a process of reflection, designed to gain a deeper understanding of their first impressions and perceptions of the app and the associated learning process.

\section{Measurement}

Using multiple measurement methods can provide a certain degree of reliability. [26] mentioned that the use of a single method is more prone to errors. Therefore, this research adopted both quantitative and qualitative methods. Quantitative data were gathered by means of a questionnaire. To ensure content validity, questionnaire items were modified from those used in previous research [13], [17], [18], [24], [27]. The questionnaire, presented in Chinese, comprised two sections, the first targeting demographic information (sex, age, department, frequency of educational app use, preferred kind of language learning app). The second section targeted the TAM variables with five-point Likert-scale items, possible answers ranging from 1 (strongly disagree) to 5 (strongly agree).

The outcomes of the reliability and validity examinations are presented in Table I. Cronbach's alpha for all variables exceeded .70, indicating high reliability [28]. Exploratory factor analysis (EFA), which explains relationships among a set of indicators with estimation of factor loadings, was performed to extract appropriate items. The EFA showed that the dataset was sound to extract seven factors $(\mathrm{KMO}=.815$, $p=.00$, all communalities $>.50$, total variance extracted $=.76)$. Confirmatory factor analysis (CFA) was then used to confirm the extracted factor structure. Construct validity (both convergent and discriminant) was examined by CFA, namely composite reliability (CR), average variance extracted (AVE), and factor loadings.

The model fit index of the confirmatory factor analysis indicates whether the research model fits the sample. Table 2 shows the model fit using a normalized chi-square $\left(\chi^{2 / d f}\right)$, the incremental fit index (IFI), the comparative fit index 
(CFI), the parsimonious comparative-fit-index (PCFI), and the root mean square error of approximation (RMSEA). All values reached those suggested. As the model fit indices confirmed the soundness of the confirmatory factor analysis, the factor loading of each item was above .70 (see Fig. 4), confirming the convergent validity of the instrument.

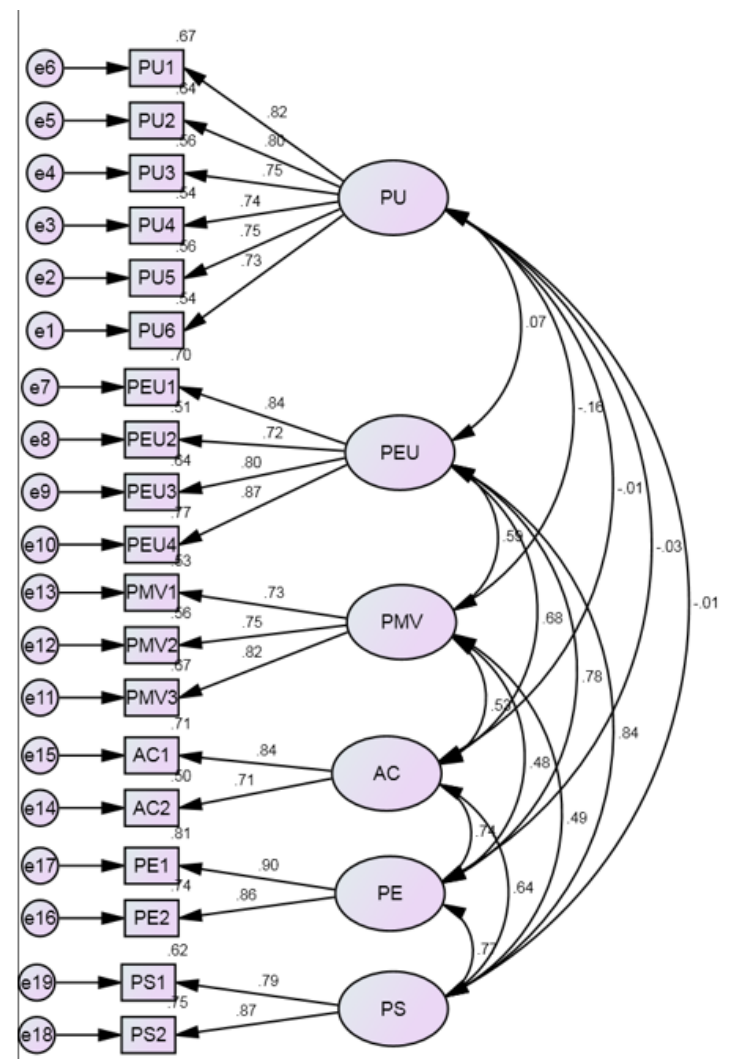

Fig. 4. Results of the confirmatory factor analysis of questionnaire items.

TABLE I: TAM QUESTIONNAIRE: VALIDITY AND RELIABILITY

\begin{tabular}{|c|c|c|}
\hline \multicolumn{3}{|c|}{ Latent variables $\quad$ Measured items } \\
\hline $\begin{array}{l}\text { Perceived } \\
\text { Usefulness } \\
\text { Cronbach's } \alpha=.89 \\
\text { CR }=.89 \\
\text { AVE }=.59\end{array}$ & $\begin{array}{l}\text { PU2 } \\
\text { PU3 } \\
\text { PU4 }\end{array}$ & $\begin{array}{l}\text { Using this app would make it easier for me to learn } \\
\text { business English. } \\
\text { Using this app to learn business English would enhance } \\
\text { my performance. } \\
\text { Using this app to learn business English would increase } \\
\text { my productivity. } \\
\text { Using this app to learn business English would enhance } \\
\text { my effectiveness. } \\
\text { Using this app to learn business English would help me } \\
\text { get better grades. } \\
\text { I find this app useful for business English learning. }\end{array}$ \\
\hline $\begin{array}{l}\text { Perceived Ease of } \\
\text { Use } \\
\text { Cronbach's } \alpha=.88 \\
\text { CR }=.88 \\
\text { AVE }=.66\end{array}$ & $\begin{array}{l}\text { PEOU1 } \\
\text { PEOU2 } \\
\text { PEOU3 }\end{array}$ & $\begin{array}{l}\text { Learning to use this app for business English learning } \\
\text { would be easy for me. } \\
\text { I would find it easy to get this app to do what I want it } \\
\text { to do for business English learning. } \\
\text { I do not face problems interacting with this app for } \\
\text { business English learning. } \\
\text { I would find this app flexible enough to interact with } \\
\text { business English learning. }\end{array}$ \\
\hline $\begin{array}{l}\text { App Characteristics } \\
\text { Cronbach's } \alpha=.75 \\
\text { CR }=.75 \\
\text { AVE }=.61\end{array}$ & $\mathrm{ACl}$ & $\begin{array}{l}\text { I think this app's characteristics (e.g., multimedia, } \\
\text { pictures, audio, and text) could provide business } \\
\text { English learning activity in a realistic environment. } \\
\text { I think this app's characteristics (e.g. multimedia, } \\
\text { pictures, audio, and text) could provide a simulated } \\
\text { business English learning environment. }\end{array}$ \\
\hline $\begin{array}{l}\text { Perceived } \\
\text { Enjoyment } \\
\text { Cronbach's } \alpha=.87+ \\
\text { CR }=.87 \\
\mathrm{AVE}=.77\end{array}$ & $\begin{array}{l}\text { PE1 } \\
\text { PE2 } \\
\end{array}$ & Using this app to learn business English is interesting. \\
\hline $\begin{array}{l}\text { Perceived Mobile } \\
\text { Value } \\
\text { Cronbach's } \alpha=.81 \\
\mathrm{CR}=.81 \\
\mathrm{AVE}=.69\end{array}$ & $\begin{array}{l}\text { PMV1 } \\
\text { PMV2 } \\
\text { PMV3 }\end{array}$ & $\begin{array}{l}\text { I know that mobile devices are media for mobile- } \\
\text { assisted language learning. } \\
\text { It is convenient to access mobile-assisted language } \\
\text { learning anywhere anytime. } \\
\text { Mobility is an outstanding advantage of mobile- } \\
\text { assisted language learning. }\end{array}$ \\
\hline $\begin{array}{l}\text { Perceived } \\
\text { Satisfaction } \\
\text { Cronbach's } \alpha=.80 \\
\mathrm{CR}=.81 \\
\mathrm{AVE}=.59\end{array}$ & $\begin{array}{l}\text { PS1 } \\
+\quad P S 2\end{array}$ & $\begin{array}{l}\text { I am satisfied with using the app as a business English } \\
\text { learning assistance tool. }\end{array}$ \\
\hline
\end{tabular}

The qualitative data for the present study comprised participants' reflections on their needs, deeper thoughts, and first impressions regarding the use of the app in learning business English. Interviews were used to capture the participants' impressions [29]. These reflection sessions allowed for follow-up questioning to better understand participant's opinions and impressions.

\begin{tabular}{lll} 
& TABLE II: CFA MODEL FIT STATISTICS \\
\hline Fit index & Suggested value & CFA model \\
\hline$\chi 2 /$ df & $<3$ & 1.76 \\
IFI & .9 & .91 \\
CFI & .9 & .90 \\
PCFI & .5 & .65 \\
RMSEA & $\leqq 0.08$ & .08 \\
\hline
\end{tabular}

\section{RESULTS}

\section{A. Descriptive Statistics}

Descriptive statistics (means and standard deviations) were taken to indicate participants' general perceptions, showing that most held positive attitudes toward using the app in learning business English, agreed that it could enhance their proficiency, and were willing to continue using it. Perceived mobile value (PMV) was the highest-scoring of the seven TAM variables, with a mean of 4.53 (recall that $5=$ strongly agree). Furthermore, all questionnaire items related to PMV scored more than 4.5 points, and these items were the highest-scoring overall. This suggests that the participants agreed that MALL was convenient, and that mobility allowed users access to a learning program at any time and place, giving them more learning opportunities and self-learning options.

Perceived ease of use achieved the second-highest mean of 4.19 , suggesting that the participants agreed that the app was simple to operate and easily did what they wanted it to do; the app required little effort in learning business English. The third-highest variable was PS, with a mean of 3.98, indicating that the participants were satisfied with the app, the learning system, and the content. This degree of satisfaction provides app designers with a good model and points of reference for future language learning apps.

In contrast, BI achieved the lowest mean of the seven variables, at 3.83, with every item scoring more than 3.5. Even this lowest mean suggests that the participants were willing to use the app on an ongoing basis, and would choose it to learn business English given the opportunity.

The above results show that most participants agreed that the design of this Business English app interface was user-friendly. Participants also enjoyed using the app to acquire knowledge and were satisfied with the learning content. The results suggest that app's use of multimedia, images, audio, animations, and text, and the opportunity to experience simulated business English environments, allowed participants to learn the contents with different ways of presentation conveniently. Participants largely agreed that the app was suitable and convenient for learning business English. As various kinds of mobile devices provide such learners with more opportunities than traditional learning approaches, it appears that the direction of learning may shift from books to technology. 


\section{B. Hypothesis Testing}

The data were further analyzed by means of the partial least square approach, a form of component-based structural equation modelling testing causal relationships among variables [30]. Fig. 4 shows the results, with the path set to be significant at the .05 level in the proposed research model. The outcomes show support for hypotheses 1, 4, 5, 6, and 8, but no support for hypotheses 2,3 , and 7 .

Despite the limitless learning allowed by mobile apps, PMV did not have a positive impact on PU $(\beta=-.275, p$ $<.05)$. Furthermore, the ACs, which aimed to provide simulations of real-life contexts, had no significant effect on PU. In terms of PE, by which learners are expected to regard a system they enjoy using as useful and easy to operate, this had a significant and positive effect on PEU $(\beta=.706, p$ $<.00)$, but not on PU. However, PEU had a significant and positive impact on PU $(\beta=.342, p<.01)$. PU, in turn, had no significant effect on PS, which is contrary to the findings of Ho (2010). Moreover, PS and BI had a significant positive relationship $(\beta=.306, p<.01)$, as did PEU and $\mathrm{BI}(\beta=.295$, $p<.01)$.

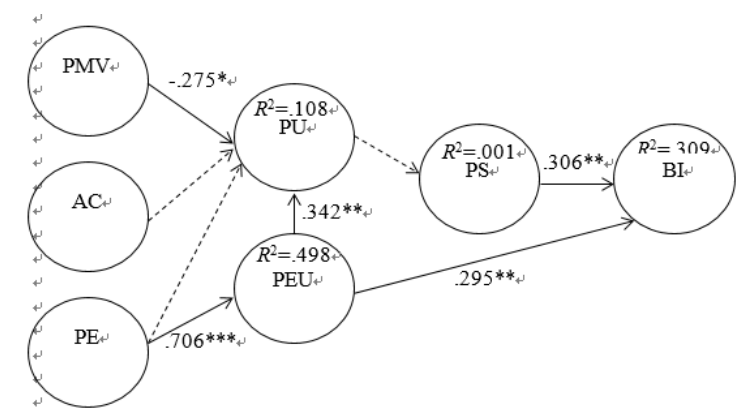

Note. $\mathrm{PMV}=$ perceived mobile value; $\mathrm{AC}=$ app characteristic; $\mathrm{PE}=$ perceived enjoyment; $\mathrm{PU}=$ perceived usefulness; $\mathrm{PEOU}=$ perceived ease of use; $\mathrm{PS}=$ perceived satisfaction; $\mathrm{BI}=$ behavioral intention $* p<.05, * * p<.01, * * * p<.00$

Fig. 5. Results of examination of proposed research model.

\section{Qualitative Data}

The participants' interview reflections were classified into three main categories, namely app functionality, learning content, and other requirements. App functionality focused on system functions, such as multimedia and pronunciation cues. Most participants made positive comments, and comments that may lead to improvements in the app, such as the following:

Participant 1: If the app could provide a vocabulary searching function it would be more valuable.

Participant 2: The way to present the correct answer in the activity part is not easy to recognize. Therefore, the instructions should be clearer.

Participant 5: Sometimes the pronouncing speaker is too fast or too slow. The article on the practical tip could use different colors to highlight the main points; it would be easier to read.

Participant 10: If the characters in the app were animated it would be more interesting.

Participant 11: If the images were animated it would be more interesting and vivid.

This feedback about functionality shows the participants' preference for learning language through animation rather than just images. A more interesting and vivid learning environment may better retain learners' attention. The suggestion of a vocabulary searching function shows that the mobile device may be regarded as a source of immediate feedback.

In terms of learning content, the app focuses on conversation, providing practical tips, exercises, and vocabulary. The participants' reflections on content highlighted several issues, as follows:

Participant 1: If the learning activity had an explanation at the end it would be more convenient and easy to understand.

Participant 3: I think after going into each topic, the small title should change from lesson one, lesson two, to looking for the right job, preparation after receiving a job offer, and so on.

Participant 4: Could provide more vocabulary, speaking, and writing functions.

Participant 7: Expect the correct answer in the learning activity. Hope it can also provide an explanation for the correct answer.

Participant 9: This app is easy to operate. And I like the learning activity part which allows repeat practicing.

Participant 12: Could add advanced vocabulary or synonyms.

These learning content suggestions show a need for various levels of vocabulary, synonyms, and antonyms within the learning content, reflecting the view of vocabulary as a basic skill when learning a language, as participants preferred being able to learn about related words simultaneously. Furthermore, participants wanted explanations about correct answers. Such explanations may reinforce learning and allow learning content to be reviewed. Participants also wanted the learning program to include listening, speaking, reading, and writing skills, rather than just listening and reading. There appears to be a need for a well-established app that includes all four language skills.

Finally, some participant feedback reflected suggestions not related to functionality or learning content, as follows:

Participant 6: This language learning app can develop in the Android market.

Participant 8: This is a very nice business English learning app. If this app can be downloaded for free, I will use it more often, thanks!

Participant 10: Hope the app is not only available for Apple devices, but also for the other mobile devices or computers.

Because the English Messenger app was only available in the Apple Store, those with an Android operating system could not download it, restricting its use. Ideally, such an app should be available across all app markets.

\section{DISCUSSIONS AND CONCLUSIOND}

This study applied the Technology Acceptance Model (TAM) in exploring learners' perceptions of a mobile app for business English learning. The data show that the TAM predicted and explained participants' perceptions of the use of the English Messenger app in learning business English, as was the case in previous research [14], [16]-[18]. Furthermore, the present results suggest that learners do 
regard perceived mobile value as an important element in using this app to learn Business English, suggesting support for the potential of employing app as a complementary teaching and learning tool for ESP courses, which has become common among learners familiar with mobile devices and apps. People currently use mobile devices and apps to accomplish a variety of tasks, experiencing mobile value in everyday life. For this reason, the value of a mobile device in learning may attract students, as reflected by the descriptive statistics reported above, which showed that participants were familiar with mobile devices and apps, and naturally appreciated the convenience of mobile learning and its advantages in enhancing their language proficiency. These results echo those of [5] who argued that the importance of MALL will attract attention of academics as well as practitioners.

Despite App characteristics being postulated as important elements for learners, the present results revealed no significant effect on the perceived usefulness of this learning app. It is an intriguing yet counterintuitive finding. A possible explanation may be the content design of the present app, which may not have matched participants' current level of proficiency. In other words, this particular app did not provide 'comprehensible input' [31] to learners. Learners may experience characteristics of this learning app, but the contents disappointed them. This outcome pointed out the importance of knowing target users' level of proficiency while designing learning app for MALL. It is suggested that app designers and English teachers should work closer to complement each other's expertise while developing the app. Another possible reason for the finding may be the sample size, which could have influenced the statistical outcomes. Future studies are encouraged to recruit more participants with various language backgrounds to increase the generalizability of research results.

The present results identified PE as a critical factor that influenced the participants' PEU, consistent with previous research revealing that enjoyment is connected to ease of use [22] but not usefulness. The data showed that the participants enjoyed using the app to acquire knowledge during the learning process, and this enjoyment reduced their effort and promoted their interest. However, the app content led to the enjoyment, rather than enjoyment leading to usefulness. Thus, app designers would do well to equip themselves with knowledge of curriculum design to improve learners' perceptions regarding usefulness.

Moreover, PEU was shown by the present study to lead to enhanced business English proficiency and to have a positive impact on BI. This finding is contrary to those of previous studies [32]-[35], which suggested that PEU was a weak variable in predicting BI. This indicates that the app was regarded as common software among the participants, who already had experience using apps. Even so, EFL learners still place high priority on PEU when making acceptance decisions.

The results also suggest that a learner who believes his or her language proficiency may be enhanced by app use will experience increased satisfaction. Thus, when learners have a high degree of satisfaction with an app, their future behavioral intention to use it to learn business English is expected to increase. In the present research, perceived usefulness was found not to be a major factor in participants' perceptions, which may indirectly influence the intention to use an app. This finding is partially in line with those of previous research [36], [37]. Future research among more diverse learners may shed light on this issue. Satisfaction was found to play a role in confirming participants' behavioral intention. In other words, perceived satisfaction became a predictor of their perceptions, the second major factor in the TAM model.

A number of limitations to the present study deserve mention. First, the number of participants was limited, restricting generalization. Users' acceptance of technology and apps ought to be investigated across a larger range of ages and regions. Second, this research used only the TAM to examine learners' perceptions of using the business English app. To explore other aspects and requirements, a multi-faceted approach may enrich future research and reveal further findings on users' thoughts. Finally, future research ought to include a control group in order to compare traditional approaches to MALL, to determine any differences in learning outcomes, and to understand the efficacy of apps.

The results of this research reveal that most participants showed a high degree of positive perceptions and a willingness to use the app on an ongoing basis. They were satisfied with the app's content and function, and considered its ease of use in determining their future BI to use it for learning business English. This suggests that the content of a learning program is a critical element for learners. In addition, it appears that PMV and PE are important elements influencing learners' perceptions. The ability to combine a range of multimedia, images, audio, animation, and text is the greatest advantage of an app, making the learning process interesting and promoting learning motivation. In addition, by integrating various types of activities and information, the learning content can enhance learners' interest. Thus, providing a simulated business English learning environment and learning activities can promote learners' motivation, making their learning process more interesting and increasing their satisfaction. A high degree of satisfaction increases learners' acceptance of an app as a learning tool. By learning through MALL, users can experience the advantages of self-learning, experiencing less pressure.

\section{CONFLICT OF INTEREST}

This study was carried out without a conflict of interest.

\section{AUTHOR CONTRIBUTIONS}

Yu-chun Wang conducted the research; Liwei Hsu analyzed the data. Both authors wrote the paper and they had approved the final version.

\section{ACKNOWLEDGMENT}

The research project reported here was financially supported by the Ministry of Education, Taiwan. 


\section{REFERENCES}

[1] P. Rogerson-Revell, "Using English for international business: A European case study," English for Specific Purposes, vol. 26, pp. 103-120, 2007.

[2] K. Hyland, International Handbook of English Language Teaching, Springer Link, 2007, doi: 10.1007/978-0-387-46301-8_28.

[3] P. Helford and R. Lei, "Using the web to deliver and enhance courses: Two case studies," in Proc. the European University Information Systems International Conference, Espoo, Finland, June 7-9, 1999.

[4] C. Tryon, "Writing and citizenship: Using blogs to teach first-year composition," Pedagogy, vol. 6, pp. 128-132, 2006.

[5] L. Hsu, "English as a foreign language learners' perception of mobile assisted language learning: A cross-national study," Computer Assisted Language Learning, vol. 26, pp. 197-213, 2013.

[6] Y. M. Huang, Y. L. Jeng, and T. C. Huang, "An educational mobile blogging system for supporting collaborative learning," Educational Technology \& Society, vol. 12, pp. 163-175, 2009.

[7] J. H. Huang, Y. R. Lin, and S. T. Chuang, "Elucidating user behavior of mobile learning: A perspective of the extended technology acceptance model," The Electronic Library, vol. 25, pp. 585-598, 2007.

[8] Y. L. Jeng, T. T. Wu, Y. M. Huang, Q. Tan, and S. J. H. Yang, “The add-on impact of mobile applications in learning strategies: A review study," Educational Technology \& Society, vol. 13, pp. 3-11, 2010.

[9] T. Y. Liu, "A context-aware ubiquitous learning environment for language listening and speaking," Journal of Computer Assisted Learning, vol. 25, pp. 515-527, 2009.

[10] D. Kim, D. Rueckert, D. J. Kim, and d. Seo, "Students' perceptions and experiences of mobile learning," Language Learning \& Technology, vol. 17, pp. 52-73, 2013.

[11] Z. Li and V. Hegelheimer, "Mobile-assisted grammar exercises: Effects on self-editing in L2 writing," Language Learning \& Technology, vol. 17, pp. 135-156, 2013.

[12] G. Stockwell, "Using mobile phones for vocabulary activities: Examining the effect of the platform," Language Learning \& Technology, vol. 14, pp. 95-110, 2010.

[13] F. D. Davis, "A technology acceptance model for empirically testing new end-user information systems: Theory and results," Ph.D. dissertation, Massachusetts Institute of Technology, Cambridge, MA 1986.

[14] Y. Lee, K. A. Kozar, and K. R. Larsen, "The technology acceptance model: Past, present, and future," Communications of the Association for Information Systems, vol. 12, pp. 752-780, 2003.

[15] F. D. Davis and V. Venkatesh, "A critical assessment of potential measurement biases in the technology acceptance model: Three experiments," International Journal of Human-Computer Studies, vol. 45, pp. 19-45, 1996.

[16] M. Y. Chuttur, "Overview of the technology acceptance model: Origins, developments and future directions," Sprouts, vol. 9, pp. 1-21, 2009.

[17] B. Y. Mah and A. N. Er, "Writing Web logs in the ESL classroom: A study of student perceptions and the technology acceptance model," Asian Journal of University Education, vol. 5, pp. 47-70, 2009.

[18] Y. M. Huang, Y. M. Huang, S. H. Huang, and Y. T. Lin, "A ubiquitous English vocabulary learning system: Evidence of active/passive attitudes vs. usefulness/ease-of-use," Computers \& Education, vol. 58 , pp. 273-282, 2012.

[19] N. M. Suki and N. M. Suki, "Users' behavior towards ubiquitous m-learning," Turkish Online Journal of Distance Education, vol. 12, pp 118-129, 2011.

[20] V. Venkatesh, "Determinants of perceived ease of use: Integrating control, intrinsic motivation, and emotion into the technology acceptance model," Information Systems Research, vol. 11, pp. 342-365, 2000.

[21] F. D. Davis, R. P. Bagozzi, R. P., and P. R. Warshaw, "Extrinsic and intrinsic motivation to use computers in the workplace," Journal of Applied Social Psychology, vol. 22, pp. 1111-1132, 1992.
[22] M. Y. Yi and Y. Hwang, "Predicting the use of web-based information systems: Self-efficacy, enjoyment, learning goal orientation, and the technology acceptance model," International Journal of Human-Computer Studies, vol. 59, pp. 431-449, 2003.

[23] J. M. Keller, "Instructional design theories and models: An overview of their current status," Motivational Design of Instruction, vol. 1, pp. 383-434, 1983.

[24] S. S. Liaw, "Investigating students' perceived satisfaction, behavioral intention, and effectiveness of e-learning: A case study of the Blackboard system," Computers \& Education, vol. 51, pp. 864-873, 2008.

[25] R. E. Mayer, Multimedia Learning, Cambridge: Cambridge University Press, 2001.

[26] M. Q. Patton, Qualitative Evaluation and Research Methods (2nd ed.), Newbury Park: Sage Publications, Inc, 1990.

[27] T. Kasser, J. Davey, and R. M. Ryan, "Motivation, dependability, and employee-supervisor discrepancies in psychiatric vocational rehabilitation settings," Rehabilitation Psychology, vol. 37, pp. 175-187, 1992.

[28] R. F. DeVellis, Scale Development: Theory and Applications, Los Angeles: Sage, 2012.

[29] J. R. Fraenkel and N. E. Wallen, How to Design and Evaluate Research in Education (5th ed.), New York: MacGraw-Hill, 2003.

[30] M. Tenenhaus, "Component-based structural equation modelling," Total Quality Management, vol. 19, pp. 871-886, 2008.

[31] S. D. Krashen, The Input Hypothesis: Issues and Implications, Addison-Wesley Longman Ltd, 1985.

[32] P. J. Hu, Y. K. Chau, O. R. L. Sheng, and K. Y. Tam, "Examining the technology acceptance model using physicians," Journal of Management Information Systems, vol. 16, pp. 91-112, 1999.

[33] M. Lee, C. Cheung, and Z. Chen, "Acceptance of Internet-based learning medium: The role of extrinsic and intrinsic motivation," Information \& Management, vol. 42, pp. 1095-1104, 2005.

[34] D. Lee and M. Lehto, "User acceptance of YouTube for procedural learning: An extension of the technology acceptance model," Computers \& Education, vol. 61, pp. 193-208, 2013.

[35] W. Wang and C. Wang, "An empirical study of instructor adoption of web-based learning systems," Computers \& Education, vol. 53, pp. 761-774, 2009.

[36] H. Chen and H. Tseng, "Factors that influence acceptance of web-based e-learning systems for the in-service education of junior high school teachers in Taiwan," Evaluating Program Planning, vol. 35, pp. 398-406, 2012.

[37] I. Liu, M. Chen, Y. Sun, D. Wible, and C. Kuo, "Extending the TAM model to explore the factors that affect intention to use an online learning community," Computers \& Education, vol. 54, pp. 600-610, 2010 .

Copyright $(5) 2020$ by the authors. This is an open access article distributed under the Creative Commons Attribution License which permits unrestricted use, distribution, and reproduction in any medium, provided the original work is properly cited (CC BY 4.0).

Yu-Chun Wang is an associate professor of Language Training Center, National Kaohsiung University of Science and Technology. Dr. Wang's research interests include computer assisted language learning and foreign language education.

Liwei Hsu is a professor of Graduate Program of Hospitality Management, National Kaohsiung University of Hospitality and Tourism. Dr. Hsu's research interests include computer assisted language learning, hospitality education/management as well as neuroscience. 